\title{
Contrasting Drought Tolerance in Two Apple Cultivars Associated with Difference in Leaf Morphology and Anatomy
}

\author{
Tuanhui Bai, ${ }^{12}$, Zhanying Li1, Chunhui Song1,2, Shangwei Song1,2, Jian Jiao, ${ }^{1,2}$, Yuchen Liu1, \\ Zhidan Dong1, Xianbo Zheng ${ }^{1,2 *}$
}

${ }^{1}$ College of Horticulture, Henan Agricultural University, Zhengzhou, China

${ }^{2}$ Henan Key Laboratory of Fruit and Cucurbit Biology, Zhengzhou, China

Email: *tuanhuibai88@163.com, *xianboz@163.com

How to cite this paper: Bai, T.H., Li, Z.Y., Song, C.H., Song, S.W., Jiao, J., Liu, Y.C., Dong, Z.D. and Zheng, X.B. (2019) Contrasting Drought Tolerance in Two Apple Cultivars Associated with Difference in Leaf Morphology and Anatomy. American Journal of Plant Sciences, 10, 709-722. https://doi.org/10.4236/ajps.2019.105051

Received: April 1, 2019

Accepted: May 10, 2019

Published: May 13, 2019

Copyright $\odot 2019$ by author(s) and Scientific Research Publishing Inc. This work is licensed under the Creative Commons Attribution International License (CC BY 4.0).

http://creativecommons.org/licenses/by/4.0/

cc) (i) Open Access

\begin{abstract}
Apple is one of the most important fruit trees in temperate zones, and is cultivated widely throughout the world. Drought stress affects the normal growth of apple tree, and further affects fruit yield and quality. The present study examined the effects of drought on photosynthesis and water use efficiency (WUE) of two apple cultivars (Honeycrisp and Yanfu 3) that differ in drought tolerance. The results showed that the photosynthetic rate decreased in response to drought stress for both cultivars, with significant differences in intensity. Values for net photosynthetic rate (Pn) in stressed Yanfu 3 remained significantly lower than in the controls, while, for Honeycrisp, only a slight drop in photosynthesis. Similarly, stomatal conductance (Gs), intercellular $\mathrm{CO}_{2}$ concentration ( $\left.\mathrm{Ci}\right)$, transpiration rate $(\mathrm{Tr})$ were markedly reduced in Yanfu 3 under drought stress. However, Honeycrisp showed only minor changes. Under drought stress, the contents of $\mathrm{Chl} \mathrm{a}, \mathrm{Chl} \mathrm{b}$ and $\mathrm{Chl} \mathrm{t}$ in Yanfu 3 were all decreased significantly compared with the control. However, little difference in Honeycrisp was noted between stressed plants and controls. Values for WUE in stressed Yanfu 3 remained higher than in the controls from day 3 until the end of the experiment, while no significant difference was observed in Honeycrisp. Furthermore, Honeycrisp also exhibited superior physiological traits, as indicated by its anatomical and morphological characteristics. Therefore, we conclude that the superior drought tolerance of Honeycrisp was due to its anatomical and morphological characteristics, which possibly contributed to the maintenance of higher photosynthetic capacity than Yanfu 3.
\end{abstract}

\section{Keywords}

Apple, Drought Stress, Photosynthesis, Water Use Efficiency, Leaf Anatomy 


\section{Introduction}

Drought stress is an important abiotic stress that strongly limits plant growth, productivity, and survival worldwide [1] [2]. It is estimated that the arid and semi-arid regions account for approximately $30 \%$ of the total land area [3]. Understanding the reaction of plants to drought conditions is important and will pave the way for improving tolerance to drought. In the long period of evolution, plant species with multiple of varieties have developed different strategies to respond, adapt and survive under drought stress conditions, including drought avoidance, escape and tolerance, all of which involve a number of physiological and molecular adaptation mechanisms [3] [4] [5] [6].

Photosynthesis is one of the physiological processes most sensitive to drought stress, and it plays a crucial role in plant physiological processes during adaptation to drought [7]. Drought has been shown to inhibit photosynthesis through stomatal limitation and non-stomatal limitation [2] [8]. Stomatal closure is one of the earliest responses of plants to drought stress, reducing transpiration and photosynthetic rate [9]. By limiting transpiration, stomatal closure can also improve water use efficiency (WUE) and therefore indirectly influence plant productivity under drought stress [10]. As drought severity increases, the photosynthesis might also be inhibited along with photosynthetic pigments degradation and perturbations of photochemical processes [8] [11].

Plants have developed a board range of threshold responses to drought, which is also related to the other processes, such as transpiration or photosynthesis and WUE [12] [13]. WUE is an important index of plant adaptability to a drought environment and it can be expressed as the ratio of net photosynthetic rate (Pn) to transpiration rate ( $\operatorname{Tr})$ [12] [14]. In general, the improvement of WUE occurs at the expense of Pn [15]. Some studies have been made to clarify the underlying mechanisms of the responses of Pn to drought in many plants [16] [17] [18]. Plants increase their WUE by reducing stomatal aperture and thereby transpiration rate under short-term drought condition, however, with prolonged drought, plants frequently also produce leaves with reduced maximum stomatal conductance resulting from altered stomatal density and/or size [19]. Plant varieties differ in their response to drought, as reported with poplar [2], olive [11], thyme [18], mulberry [20] and apple [21].

Apple (Malus domestica Borkh.), one of the most economically important fruits worldwide, often suffers from drought stress, which seriously affects apple productivity. In arid and semi-arid regions such as Northwest China, drought often occurs in spring and early summer, thereby directly affecting the growth and fruit quality of apple. It has been classified as one of the major adversities for apple. Although much research has been done to evaluate the physiological and/or biochemical responses of apple cultivars/species to drought stress [12] [21] [25], few studies have examined the effects of drought on leaf morphology and anatomy of apple differing in contrasting drought tolerance. In our previous study, considerable differences in drought tolerance among 6 apple cultivars 
were observed. Honeycrisp was tolerant to drought while Yanfu 3 was sensitive. However, those differences in response to drought have not been well characterized between the two cultivars. Therefore, our objective was to determine how these two cultivars differ in their mechanisms for coping with drought.

\section{Materials and Methods}

\subsection{Plant Materials and Experimental Design}

Two-year-old apple trees of two cultivars (M. domestica Borkh. cv. Honeycrisp and M. domestica Borkh cv. Yanfu 3) plants grafted on M9-T337 were used in present study. The trees were grown at a spacing of $3.5 \mathrm{~m} \times 1 \mathrm{~m}$ at Henan Agricultural University Experiment Station, Zhengzhou, China $\left(34^{\circ} 47^{\prime} \mathrm{N}, 113^{\circ} 39^{\prime} \mathrm{E}\right)$. The trees were trained as a central leader system and they were approximately $2.5 \mathrm{~m}$ tall. The plants received standard horticultural practices, diseases and pest control. The trees were randomly assigned to one of the following two treatments in July 2017. One half were exposed to progressive drought by withholding irrigation, the other half (CK) were watered to a relative soil water content of $65 \%$. There were four replications for each treatment with three trees per replicate. At $0,3,6,9,12$ and 15 days after treatment, gas exchange parameters were determined and leaf samples were taken from the fully expanded leaves to measure leaf chlorophyll and relative water content.

\subsection{Photosynthetic Measurements}

Photosynthetic measurements were determined with portable photosynthesis system (Li-6400XT, LICOR, Lincoln, Nebraska, USA). Between 09:00 and 11:00 (when light intensity was $1000-1200 \mu \mathrm{mol} \cdot \mathrm{m}^{-2} \cdot \mathrm{s}^{-1}$ and temperature was $28^{\circ} \mathrm{C}$ $31^{\circ} \mathrm{C}$ ), Pn, Gs, Ci and $\mathrm{Tr}$ were recorded from fully expanded and mature leaves. Six plants per cultivar were chosen, and one leaf per plant per cultivar were measured, for an average of 6 measurements per cultivar. After 9 days of drought stress, diurnal various in photosynthetic were measured using the Li-Cor transparent chamber. WUE was calculated as Pn/Gs.

\subsection{Photosynthetic Pigments Measurements}

Chlorophyll was extracted and assayed according to Porra et al. [22]. $0.1 \mathrm{~g}$ leaf tissue in $80 \%(\mathrm{v} / \mathrm{v})$ acetone at room temperature. After centrifugation at $11,000 \mathrm{~g}$ for $8 \mathrm{~min}$, values were measured at $\mathrm{A}_{663}, \mathrm{~A}_{645}$ and $\mathrm{A}_{470}$ with a spectrophotometer (UV-1700; SHIMADZU, Kyoto, Japan). Total chlorophyll (Chl t), chlorophyll a (Chl a) and chlorophyll $b(\mathrm{Chl} b$ ) were calculated according to the equations

\subsection{Leaf Relative Water Content}

Relative water content (RWC) was assessed as previously described by Smirnoff [23]. $\mathrm{RWC}=[($ fresh weight - dry weight $) /($ saturated weight - dry weight $)] \times 100 \%$, saturated weight was the weight after re-hydrating for $24 \mathrm{~h}$ at $5^{\circ} \mathrm{C}$, and dry weight was the weight of leaf oven-dried for $48 \mathrm{~h}$ at $70^{\circ} \mathrm{C}$. 


\subsection{Leaf Anatomical Observation}

Completely expanded leaves were collected and fixed in formalin: acetic acid: ethanol (3:1:1, v:v:v) at $4^{\circ} \mathrm{C}$ [24]. After fixation, the samples were dehydrated in a series of ethanol concentrations: $30 \%, 50 \%, 70 \%, 90 \%$, and $100 \%(\mathrm{v} / \mathrm{v})$ ethanol, for 15 min each. After infiltration, the samples were embedded. 3- $\mu$ m-thick sections were cut with an ultramicrotome (Leica EM UC6) under light microscopy. Photographs of leaf sections were taken and total 20 measurements were conducted for each of the parameters for each cultivar using computer-aided image measurement software program Image-pro plus 6.0 (Media Cybernetics, Inc., Rockville, MD, USA). Stomatal density was determined by counting the stomata in six different sections of the leaf under $200 \times$ magnification.

\subsection{Statistical Analysis}

All statistical analyses were performed using the IBM SPSS Statistics 17.0. Results were represented as the means \pm standard errors. Significant differences between treatments were separated by the least significant difference (LSD) test at $P<0.05$ probability level.

\section{Results}

\subsection{Photosynthesis Response to Drought}

The photosynthetic rate of two apple cultivars decreased in response to drought stress, with differences (Figure 1(A) and Figure 1(B)). Pn in stressed Yanfu 3 remained significantly lower than in the controls from day 3, while, for Honeycrisp, only a slight drop in photosynthesis was noted. These decreases in Pn were also accompanied by reduced Gs values in both cultivars (Figure $1(C)$ and Figure 1(D)). Furthermore, the decline was more drastic in Yanfu 3 than in Honeycrisp. After 15 days of treatment, Gs of Honeycrisp were reduced by $12.48 \%$, compared with the control, while the decrease in Gs of Yanfu 3 was $35.66 \%$. Ci of leaves also decreased significantly under drought stress. However, those levels were always greater in Yanfu 3 than in Honeycrisp compared with the control. In comparison, $\operatorname{Tr}$ of apple leaves was decreased in stressed plants of both cultivars. Compared with the control, at Days 6, 9, 12and 15 those declines in Yanfu 3 were $83.34 \%, 24.03 \%, 73.38 \%$ and $44.75 \%$ respectively, for Honeycrisp versus only $7.38 \%, 25.27 \%, 8.45 \%$ and $16.98 \%$, respectively (Figure $1(\mathrm{G})$ and Figure $1(\mathrm{H}))$.

\subsection{Diurnal Various of Photosynthetic Parameters}

The diurnal various in Pn, Gs, $\mathrm{Ci}$ and $\mathrm{Tr}$ observed at day 9 of treatment are shown in Figure 2. The diurnal variation trend of Pn of both cultivars was similar, showing a distinct the phenomenon of midday depression of photosynthesis. Values for Pn in stressed Yanfu 3 remained significantly lower than in the controls from 8:00 am until 6:00 pm, while, in Honeycrisp, only a slight drop in photosynthesis was noted (Figure 2(A) and Figure 2(B)), indicating that Ho- 
neycrisp was more tolerance to drought. Gs of both cultivars decreased gradually from $8 \mathrm{am}$ in the morning to $6 \mathrm{pm}$ in the afternoon. The degree of this response differed markedly between stressed cultivars, with gs from Yanfu 3 remaining significantly lower than the controls from 8:00 am to 6:00 pm. For Honeycrisp, however, such significant decreases were recorded only in the first two hours, with little difference being seen afterward when compared with the control (Figure 2(C) and Figure 2(D)). By comparison, for Yanfu 3, significant decreases in Ci were recorded from 8:00 to 12:00. However, no difference in Ci was noted between stressed Honeycrisp and the controls from 8:00 to 18:00 (Figure 2(E) and Figure 2(F)). The diurnal various in $\operatorname{Tr}$ of both control cultivars was similar, showing a single-ridged curve (Figure $2(\mathrm{G})$ and Figure $2(\mathrm{H})$ ). $\mathrm{Tr}$ decreased in response to drought stress for both cultivars, with significant differences in intensity observed. Values for Tr in stressed Yanfu 3 remained significantly lower than in the controls from 8:00 to 18:00, while, in Honeycrisp, only a slight drop in Tr was noted.

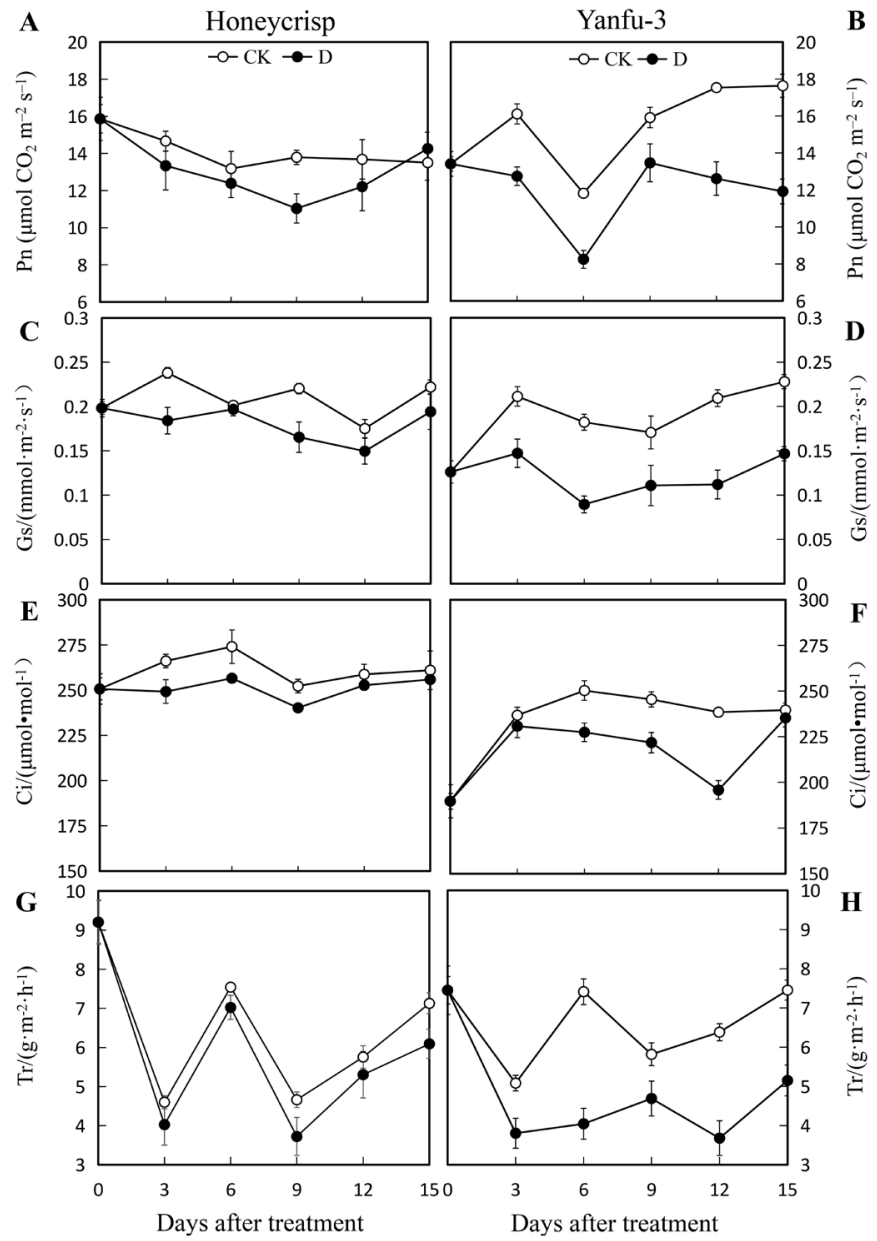

Figure 1. Changes of net photosynthetic rate $(\mathrm{Pn})$, stomatal conductance (Gs), internal $\mathrm{CO}_{2}$ concentration $(\mathrm{Ci})$ and transpiration $(\mathrm{Tr})$ of two cultivars under drought stress. Data are mean values \pm standard errors $(n=6)$. CK represents control and D represents drought. 


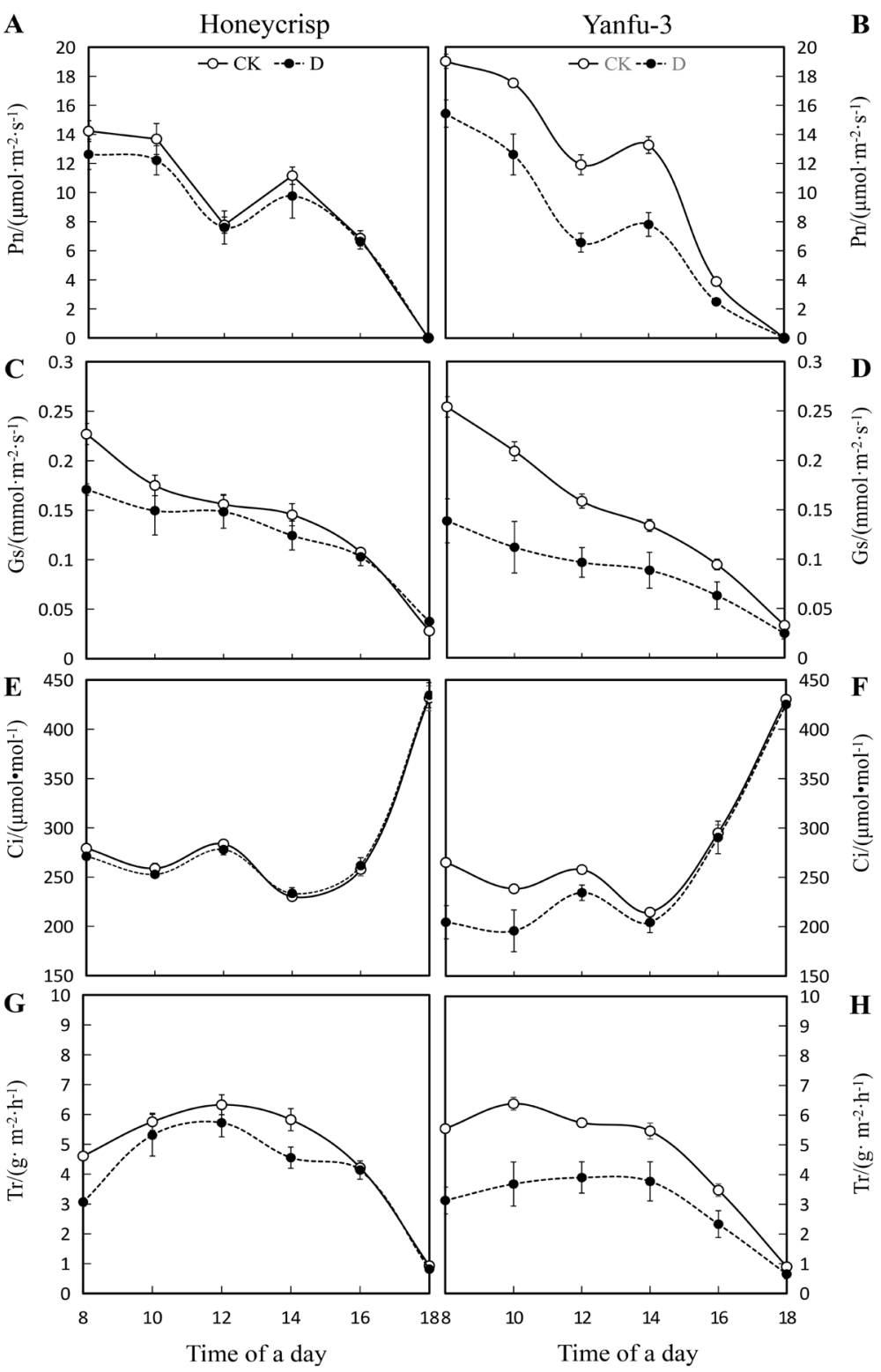

Figure 2. Curves of diurnal variation of net photosynthetic rate (Pn), stomatal conductance $(\mathrm{Gs})$, internal $\mathrm{CO}_{2}$ concentration $(\mathrm{Ci})$ and transpiration $(\mathrm{Tr})$ of two cultivars under drought stress. Data are mean values \pm standard errors $(n=6)$. CK represents control and D represents drought.

\subsection{Changes of Photosynthetic Pigments}

Under drought stress, the contents of $\mathrm{Chl} \mathrm{a}, \mathrm{Chl} \mathrm{b}$ and $\mathrm{Chl} \mathrm{t}$ in Yanfu 3 were all decreased significantly from day 3 compared with the control, at Days 9, declines were $6.46 \%, 24.97 \%$ and $13.64 \%$ respectively. However, little difference was noted between stressed plants and controls afterward in Honeycrisp (Figure 3). Ratio of $\mathrm{Chl} \mathrm{a} / \mathrm{Chl} \mathrm{b}$ in stressed Yanfu 3 remained significantly higher than in the controls from day 3. By comparison, for Honeycrisp, little difference was noted between stressed plants and controls afterward (Figure 3(E) and Figure $3(\mathrm{~F}))$. 


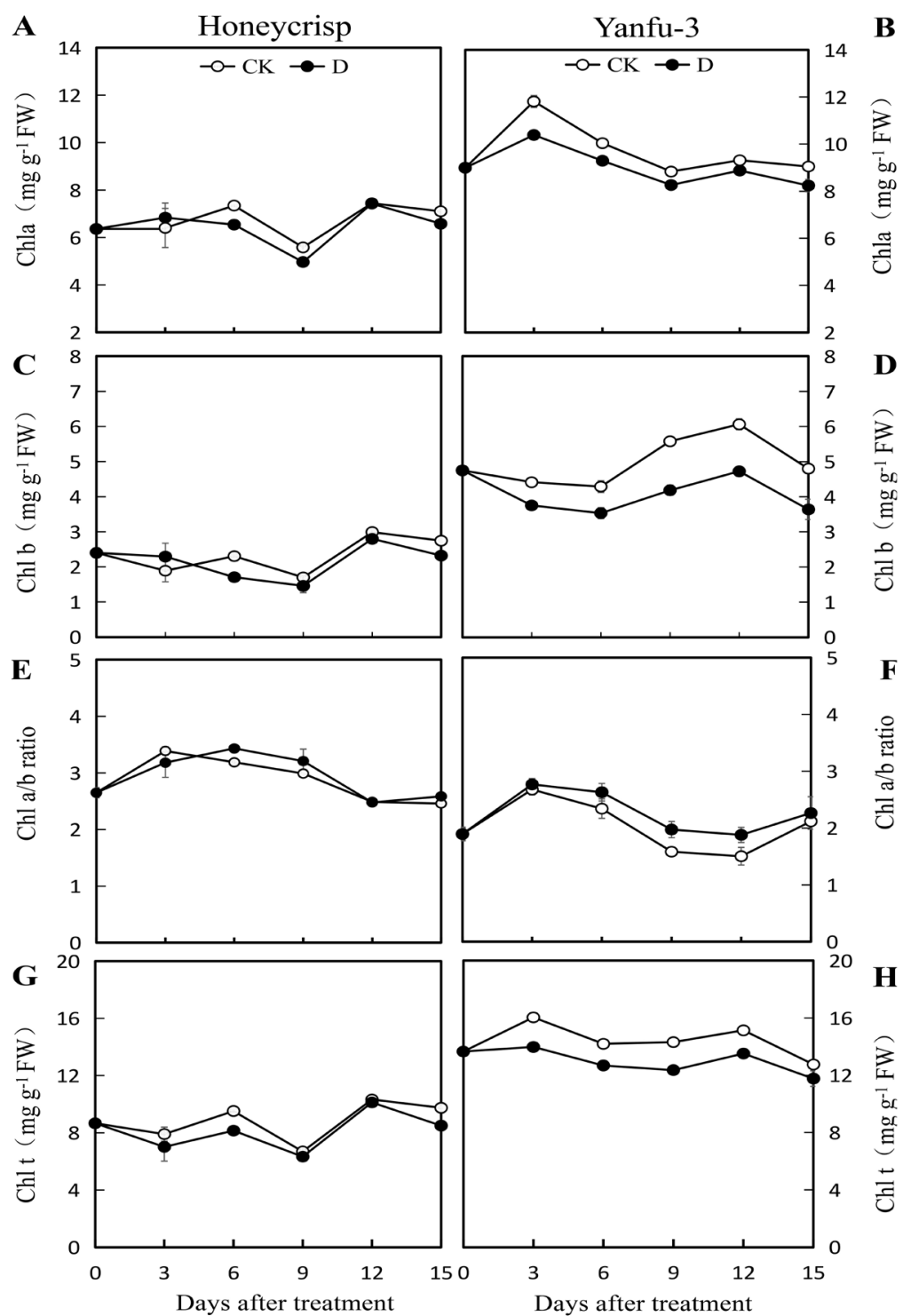

Figure 3. Changes in contents of $\mathrm{Chl} \mathrm{a,} \mathrm{Chl} \mathrm{b} \mathrm{Chl} \mathrm{t} \mathrm{and} \mathrm{the} \mathrm{Chl} a / b$ ratio of two cultivars under drought stress. Data are mean values \pm standard errors (n =6). $\mathrm{CK}$ represents control and $\mathrm{D}$ represents drought.

\subsection{Water Use Efficiency Response to Drought}

WUE of both cultivars increased in response to drought stress throughout the treatment period, with significant differences in intensity observed (Figure 4). Values for WUE in stressed Yanfu 3 remained higher than in the controls from day 3 until the end of the experiment, while no significant difference was observed in Honeycrisp.

\subsection{Changes in Leaf Relate Water Content}

For both cultivars, no significant changes in leaf RWC were recorded for both cultivars within the first 3 days of drought treatment compared with their controls (Figure 5). Continued stress induced a increase at day 9 for Honeycrisp, 
with little difference being seen afterward when compared with the control. However, for Yanfu 3, such significant decreases were recorded in the first 6 days of drought, with significant difference being seen afterward when compared with the control.

\subsection{Leaf Morphology and Anatomy}

The morphological characteristics of two apple cultivars were significantly different. The leaves of Honeycrisp were curled, while the leaves of Yanfu 3 were flat (Figure 6). Honeycrisp exhibited significantly greater leaf length, leaf area and fresh leaf weight compared to Yanfu 3 (Table 1). Similarly, Honeycrisp had thicker leaves with thicker cuticle and longer palisade cells, while Yanfu 3 had thinner and shorter palisade cell (Figure 6). The SP was thicker in Honeycrisp than Yanfu 3 (Table 2). However, little difference in the thickness of UEC and LEC was noted between both cultivars.

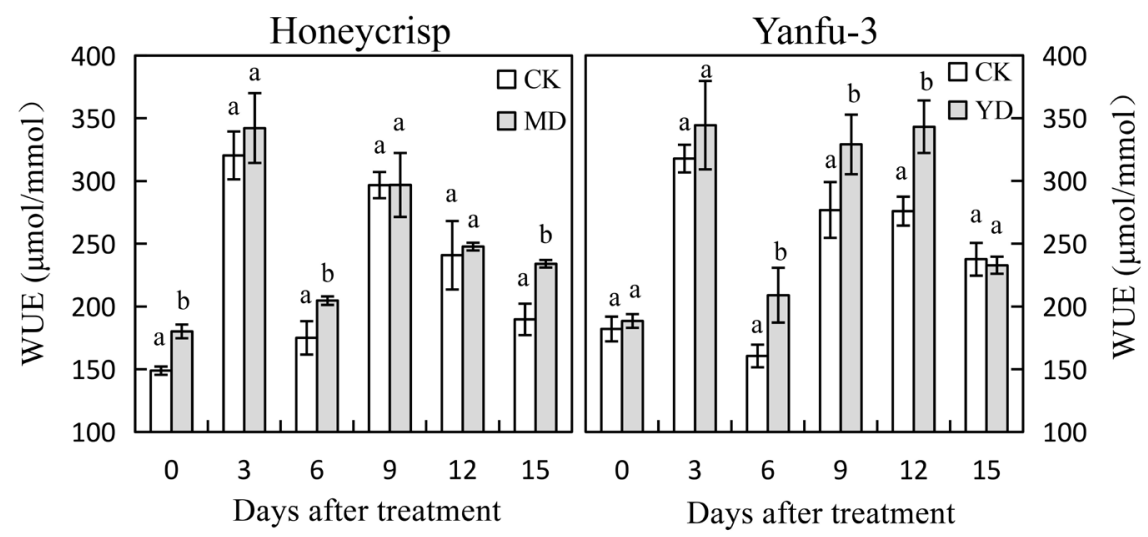

Figure 4. Changes of Water use efficiency (WUE) of two cultivars under drought stress. Data are mean values \pm standard errors $(n=6)$. Means not followed by same letters indicate significant differences between control and stressed plants $(P<0.05$, LSD test). CK represents control and $\mathrm{D}$ represents drought.

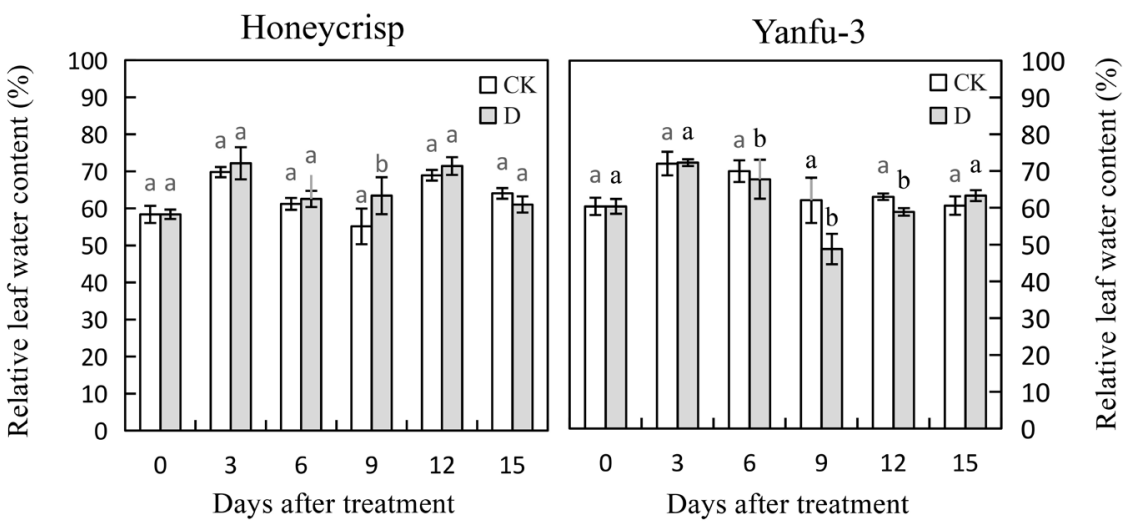

Figure 5. Changes of leaf relative water content of two cultivars under drought stress. Data are mean values \pm standard errors $(n=6)$. Means not followed by same letters indicate significant differences between control and stressed plants $(P<0.05$, LSD test). CK represents control and D represents drought. 

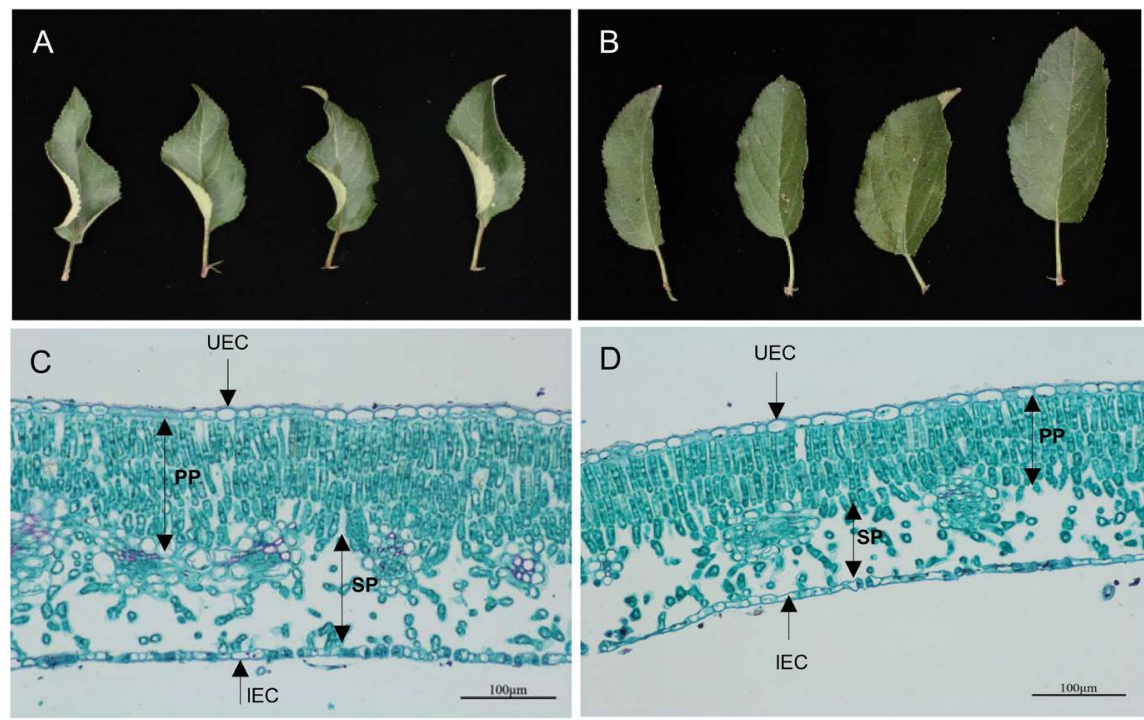

Figure 6. Leaf morphology and anatomy of two apple cultivars. Leaf cross sections showing the upper epidermis cell (UEC), lower epidermis cell (LEC), palisade parenchyma (PP) and spongy parenchyma (SP) under a light microscope. A, C: Honeycrisp; B, D: Yanfu 3.

Table 1. Comparison of leaf morphological characteristics of Honeycrisp and Yanfu-3. Data are mean values \pm standard errors $(n=10)$. Different letters in the same column indicate a significant difference between both apple cultivars at $\mathrm{P}<0.05$, LSD test.

\begin{tabular}{ccccc}
\hline Cultivars & Length $(\mathrm{cm})$ & Width $(\mathrm{cm})$ & Fresh weight $(\mathrm{g})$ & Area $\left(\mathrm{cm}^{2}\right)$ \\
\hline Honeycrisp & $9.116 \pm 0.62 \mathrm{a}$ & $5.158 \pm 0.38 \mathrm{a}$ & $1.1256 \pm 0.218 \mathrm{a}$ & $34.28 \pm 3.207 \mathrm{a}$ \\
Yanfu-3 & $7.306 \pm 0.68 \mathrm{~b}$ & $4.812 \pm 0.48 \mathrm{~b}$ & $0.9493 \pm 0.181 \mathrm{~b}$ & $27.37 \pm 4.835 \mathrm{~b}$ \\
\hline
\end{tabular}

Table 2. Leaf anatomical structure and stomatal density of Honeycrisp and Yanfu-3 Data are mean values \pm standard errors $(n=10)$. Different letters in the same column indicate a significant difference between both apple cultivars at $\mathrm{P}<0.05$, LSD test.

\begin{tabular}{|c|c|c|c|c|c|c|}
\hline \multirow[b]{2}{*}{ Cultivars } & \multicolumn{5}{|c|}{ Thickness $(\mu \mathrm{m})$} & \multirow{2}{*}{$\begin{array}{c}\text { Stomatal } \\
\text { density } \\
\left(\mathrm{mm}^{-2}\right)\end{array}$} \\
\hline & Leaf blade & $\begin{array}{l}\text { Upper } \\
\text { epidermis }\end{array}$ & $\begin{array}{l}\text { Lower } \\
\text { epidermis }\end{array}$ & $\begin{array}{c}\text { Palisade } \\
\text { parenchyma }\end{array}$ & $\begin{array}{c}\text { Spongy } \\
\text { parenchyma }\end{array}$ & \\
\hline Honeycrisp & $292.2 \pm 14.6 \mathrm{a}$ & $1.47 \pm 0.002 \mathrm{a}$ & $9.7 \pm 0.001 \mathrm{a}$ & $140.1 \pm 0.009 \mathrm{a}$ & $127 \pm 0.135 \mathrm{a}$ & $4.46 \pm 0.28 \mathrm{a}$ \\
\hline Yanfu-3 & $218.6 \pm 15.6 b$ & $1.59 \pm 0.002 \mathrm{a}$ & $8.4 \pm 0.001 \mathrm{a}$ & $97.5 \pm 0.003 b$ & $96 \pm 0.101 \mathrm{~b}$ & $3.89 \pm 0.15 b$ \\
\hline
\end{tabular}

\section{Discussion}

Drought as the most important abiotic stress has deleterious effects on plants. It has long been recognized that crop productivity and yield can be limited by insufficient photosynthesis owing to drought [16] [20] [25]. Stomatal and non-stomatal limitation of photosynthesis causes a decrease in Pn [2] [8]. The present study showed a decrease in Pn of two apple cultivars under drought conditions. Although two apple cultivars showed similar responses, Pn in stressed Yanfu 3 remained significantly lower than in the controls from day 3, while, For Honeycrisp, only a slight drop in photosynthesis was noted. The 
present study indicated that Yanfu 3 is sensitive to drought and that this cultivar showed a greater reduction in Pn under drought. By contrast, Honeycrisp was less sensitive to drought and showed a correspondingly lower reduction in Pn. These differences suggest that Honeycrisp utilizes a better protective mechanism for retaining higher photosynthetic capacity under drought. The photosynthetic rate reflects the degree of plants drought tolerance [1]. Pn is affected by endogenous factors related to leaf age, leaf weight and Chl content, leaf morphology and anatomy, etc. [11] [20] [26] [27] [28]. In this study, Honeycrisp and Yanfu 3 showed a clear difference in morphological and anatomical parameters between both cultivars under well-watered conditions. This contrast in drought tolerance is linked to differences in their photosynthetic capacity and anatomical characteristics.

Many studies have reported that drought decreased Gs and Ci [9] [10] [27]. According to the concomitant decrease in $\mathrm{Ci}$ and $\mathrm{Gs}$ of both cultivars, drought caused stomatal limitation on photosynthesis (Figure 1). This would suggest a common leaf adaption to drought on the basis of similar studies in olive [11] and apple [12]. The reduction in Pn has previously been caused by stomatal closure, which reduces the $\mathrm{CO}_{2}$ concentration within leaves [21] [29]. As another reflection of photosynthetic activity, the diurnal various in $\mathrm{Pn}, \mathrm{Gs}, \mathrm{Ci}$ and $\mathrm{Tr}$ observed at day 9 of treatment are shown in Figure 2. The diurnal variation trend of Pn of both cultivars was similar, showing a "midday depression" pattern, decreased from the dawn and reached a minimum at noon (12:00), then followed by a recovery in the afternoon. The occurrence of "midday depression" was considered a stress effect or an adaptation strategy of apple to drought. This adaptation strategy is also observed in guava tree [30]. In addition, the degree of this response differed markedly between stressed cultivars, with Pn, Gs, Ci and Tr for Yanfu 3 remaining significantly lower than the controls. For Honeycrisp, however, little difference being seen when compared with the control. Therefore, these differences in photosynthesis characteristics indicate contrasting drought tolerance and adaptation between two apple cultivars. The capacity for two apple cultivar to adapt to drought stress might be associated with their contrast leaf morphology and anatomy (Figure 6). Some genotypes within a species develop adaptations to drought by physiological anatomical changes [11] [31].

Chlorophyll is the main photosynthetic pigment in plants, which directly involves in the process of light energy absorption, transfer and transformation [32]. Chlorophyll is susceptible to environmental stresses [33]. It is reported that a decline in photosynthesis is caused by the loss of chlorophyll and it is a generally used parameter for measuring the degradation of the photosynthetic apparatus [34]. In this study, decrease in $\mathrm{Chl} \mathrm{a,} \mathrm{Chl} \mathrm{b} \mathrm{and} \mathrm{chl} \mathrm{t} \mathrm{content} \mathrm{were} \mathrm{detected}$ in both apple cultivars under drought (Figure 5). Despite the similar chlorophyll and photosynthetic response of both apple cultivars to drought, some interesting differences in intensity are noted. For stressed Yanfu 3, Pn and Chl a, Chl b and chl $t$ remained significantly lower than in the controls. For Honeycrisp, only a small decline in chlorophyll was observed, resulting in just a slight drop in Pn. 
These differences suggest that Honeycrisp utilizes a better protective mechanism for retaining higher chlorophyll contents and photosynthetic capacity than Yanfu 3. Lower chlorophyll content and photosynthetic capacity consistently occurred in stressed Yanfu 3. The results also suggest that the decline of Pn may be partly caused the loss of chlorophyll caused by drought [34]. Additionally, drought stress also affected the composition of photosynthetic pigments. $\mathrm{Chl} a / b$ ratio increased was detected in two apple cultivars under drought stress. A similar result was observed in pepper leaves exposed to $\mathrm{NaCl}$-stress [35].

WUE is an important physiological adaptation, which can improve crop productivity under drought stress [12] Many studies have repotted that the improved WUE is at the expense of Pn [13] [15]. Our results showed that drought decreased the Pn, accompanied by increasing WUE in apple leaves. Han et al. [14] also reported that drought treatment could mitigate against the decrease in Pn of the cotton while enhancing WUE. In addition, Values for WUE in stressed Yanfu 3 remained higher than in the controls from day 3 until the end of the experiment, while no significant difference was observed in Honeycrisp. Under drought, the Tr in Yanfu 3 decreased more than in Honeycrisp, thus its WUE was enhanced by drought. We conclude that Honeycrisp may be linked in maintaining its photosynthetic rate under drought stress.

\section{Conclusion}

Photosynthesis (Pn, Gs, $\mathrm{Ci}$ and $\mathrm{Tr}$ ) and photosynthetic pigments (Chl a, Chl b and $\mathrm{Chl}$ t) were significantly affected by drought stress, with significant differences in intensity between both apple cultivars. Yanfu 3 is sensitive to drought and this cultivar shows a greater decline in photosynthetic rate under drought. In contrast, Honeycrisp is more tolerant of drought stress and can sustain higher photosynthetic performance than Yanfu 3. Honeycrisp and Yanfu 3 also showed a clear difference in morphological and anatomical parameters between both cultivars. Honeycrisp was characterized by larger leaf area, greater LW, PP and SP as compared to those in Yanfu 3. This contrast in drought tolerance is linked to differences in their photosynthetic capacity, morphological and anatomical characteristics.

\section{Acknowledgements}

This work was supported by the National Natural Science Foundation of China (31872058), Henan Natural Science Foundation (162300410132), Program of Young-backbone Teacher of University in Henan Province (2018GGJS029) and Major Science and Technology Project in Henan Province (151100110900). The authors are grateful to Mr. Duomin Zhang for their help with photosynthesis system.

\section{Conflicts of Interest}

The authors declare no conflicts of interest regarding the publication of this paper. 


\section{References}

[1] Chaves, M.M., Flexas, J. and Pinheiro, C. (2009) Photosynthesis under Drought and Salt Stress, Regulation Mechanisms from Whole Plant to Cell. Annals of Botany, 103, 551-560. https://doi.org/10.1093/aob/mcn125

[2] Barchet, G.L., Dauwe, R., Guy, R.D., Schroeder, W.R., Soolanayakanahally, R.Y., Campbell, M.M. and Mansfield, S.D. (2014) Investigating the Drought-Stress Response of Hybrid Poplar Genotypes by Metabolite Profiling. Tree Physiology, 34, 1203-1219. https://doi.org/10.1093/treephys/tpt080

[3] Sivakumar, M.V.K., Das, H.P. and Brunini, O. (2005) Impacts of Present and Future Climate Variability and Change on Agriculture and Forestry in the Arid and Semi-Arid Tropics. Climatic Change, 70, 31-72. https://doi.org/10.1007/s10584-005-5937-9

[4] Benfey, P.N. and Mitchell-Olds, T. (2008) From Genotype to Phenotype: Systems Biology Meets Natural Variation. Science, 320, 495-497.

https://doi.org/10.1126/science.1153716

[5] Brodribb, T.J. and McAdam, S.A.M. (2017) Evolution of the Stomatal Regulation of Plant Water Content. Plant Physiology, 174, 639-649. https://doi.org/10.1104/pp.17.00078

[6] Reynolds, V.A., Anderegg, L.D.L., Loy, X., HilleRisLambers, J. and Mayfield, M.M. (2018) Unexpected Drought Resistance Strategies in Seedlings of Four Brachychiton Species. Tree Physiology, 38, 664-677. https://doi.org/10.1093/treephys/tpx143

[7] Li, L., Gu. W., Li, J., Li, C., Xie, T., Qu, D., Meng, Y., Li, C. and Wei, S. (2018) Exogenously Applied Spermidine Alleviates Photosynthetic Inhibition under Drought Stress in Maize (Zea mays L.) Seedlings Associated with Changes in Endogenous Polyamines and Phytohormones. Plant Physiology and Biochemistry, 129, 35-55. https://doi.org/10.1016/j.plaphy.2018.05.017

[8] Yin, C., Pen, Y., Zan, R., Zhu, Y. and Li, C. (2005) Adaptive Responses of Populus kangdingens Is to Drought Stress. Physiologia Plantarum, 123, 445-451.

https://doi.org/10.1111/j.1399-3054.2005.00477.x

[9] Dwelle, R.B., Hurley, P.J. and Pavek, J.J. (1983) Photosynthesis and Stomatal Conductance of Potato Clones (Solanum tuberosum L.). Plant Physiology, 72, 172-176. https://doi.org/10.1104/pp.72.1.172

[10] Hua, W., Yan, X., Xiao, Y., Zeng, J., Qi, H. and Ogweno, J.O. (2013) 24-Epibrassinosteroid Alleviate Drought-Induced Inhibition of Photosynthesis in Capsicum annuum. Scientia Horticulturae, 150, 232-237. https://doi.org/10.1016/j.scienta.2012.11.012

[11] Boughalleb, F. and Hajlaoui, H. (2011) Physiological and Anatomical Changes Induced by Drought in Two Olive Cultivars (cv Zalmati and Chemlali). Acta Physiologiae Plantarum, 33, 53-65. https://doi.org/10.1007/s11738-010-0516-8

[12] Liu, B., Li, M., Cheng, L., Liang, D., Zou, Y. and Ma, F. (2012) Influence of Rootstock on Antioxidant System in Leaves and Roots of Young Apple Trees in Response to Drought Stress. Plant Growth Regulation, 67, 247-256. https://doi.org/10.1007/s10725-012-9683-5

[13] Forner, A., Valladares, F., Bonal, D., Granier, A., Grossiord, C. and Aranda, I. (2018) Extreme Droughts Affecting Mediterranean Tree Species' Growth and Water-Use Efficiency: The Importance of Timing. Tree Physiology, 38, 1127-1137. https://doi.org/10.1093/treephys/tpy022

[14] Han, J., Meng, H., Wang, S., Jiang, C., Liu, F., Zhang, W. and Zhang, Y. (2016) Va- 
riability of Mesophyll Conductance and Its Relationship with Water Use Efficiency in Cotton Leaves under Drought Pretreatment. Journal of Plant Physiology, 194, 61-71. https://doi.org/10.1016/j.jplph.2016.03.014

[15] Aranda, I., Pardos, M., Puértolas, J., Jiménez, M.D. and Pardos, J.A. (2007) Water-Use Efficiency in Cork Oak (Quercus suber) Is Modified by the Interaction of Water and Light Availabilities. Tree Physiology, 27, 671-677.

https://doi.org/10.1093/treephys/27.5.671

[16] Osakabe, Y., Osakabe, K., Shinozaki, K. and Tran, L.S.P. (2014) Response of Plants to Water Stress. Frontiers in Plant Science, 5, 1-8. https://doi.org/10.3389/fpls.2014.00086

[17] Mashilo, J., Odindo, A.O., Shimelis, H.A., Musenge, P., Tesfay, S.Z. and Magwaza, L.S. (2017) Drought Tolerance of Selected Bottle Gourd [Lagenaria siceraria (Molina) Standl.] Landraces Assessed by Leaf Gas Exchange and Photosynthetic Efficiency. Plant Physiology and Biochemistry, 120, 75-87. https://doi.org/10.1016/j.plaphy.2017.09.022

[18] Ashrafi, M., Azimi-Moqadam, M., Moradi, P., MohseniFard, E., Shekari, F. and Kompany-Zareh, M. (2018) Effect of Drought Stress on Metabolite Adjustments in Drought Tolerant and Sensitive Thyme. Plant Physiology and Biochemistry, 132, 391-399. https://doi.org/10.1016/j.plaphy.2018.09.009

[19] Franks, P.J., Doheny-Adams, T.W., Britton-Harper, Z.J. and Gray, J.E. (2015) Increasing Water-Use Efficiency Directly through Genetic Manipulation of Stomatal Density. New Phytologist, 207, 188-195. https://doi.org/10.1111/nph.13347

[20] Reddy, K.S., Sekhar, K.M. and Reddy, A.R. (2017) Genotypic Variation in Tolerance to Drought Stress Is Highly Coordinated with Hydraulic Conductivity-Photosynthesis Interplay and Aquaporin Expression in Field-Grown Mulberry (Morus spp.). Tree Physiology, 37, 926-937. https://doi.org/10.1093/treephys/tpx051

[21] Ma, P., Bai, T. and Ma, F. (2015) Effects of Progressive Drought on Photosynthesis and Partitioning of Absorbed Light in Apple Trees. Journal of Integrative Agriculture, 14, 681-690. https://doi.org/10.1016/S2095-3119(14)60871-6

[22] Porra, R.J., Thompson, W.A. and Kriedemann, P.E. (1989) Determination of Accurate Extinction Coefficients and Simultaneous Equations for Assaying Chlorophylls a and b Extracted with Four Different Solvents: Verification of the Concentration of Chlorophyll Standards by Atomic Absorption Spectroscopy. Biochimica et Biophysica Acta, 975, 384-394. https://doi.org/10.1016/S0005-2728(89)80347-0

[23] Smirnoff, N. (1993) The Role of Active Oxygen in the Response of Plants to Water Deficit and Desiccation. New Phytologist, 125, 27-58. https://doi.org/10.1111/j.1469-8137.1993.tb03863.x

[24] Karnovsky, M.J. (1965) A Formaldehyde-Glutaraldehyde Fixative of High Osmolality for Use in Electron Microscopy. The Journal of Cell Biology, 27, 137-138.

[25] Zhou, S., Li, M., Guan, Q., Liu, F., Zhang, S., Chen, W., Yin, L., Qin, Y. and Ma, F. (2015) Physiological and Proteome Analysis Suggest Critical Roles for the Photosynthetic System for High Water-Use Efficiency under Drought Stress in Malus. Plant Science, 236, 44-60. https://doi.org/10.1016/j.plantsci.2015.03.017

[26] Cregg, B.M. (1994) Carbon Allocation, Gas Exchange, and Needle Morphology of Pinus ponderosa Genotypes Known to Differ in Growth and Survival under Imposed Drought. Tree Physiology, 14, 883-898. https://doi.org/10.1093/treephys/14.7-8-9.883

[27] Galmés, J., Medrano, H. and Flexas, J. (2007) Photosynthetic Limitations in Response to Water Stress and Recovery in Mediterranean Plants with Different 
Growth Forms. New Phytologist, 175, 81-93.

https://doi.org/10.1111/j.1469-8137.2007.02087.x

[28] Bhusala, N., Bhusal, S.J. and Yoona, T. (2018) Comparisons of Physiological and Anatomical Characteristics between Two Cultivars in Bi-Leader Apple Trees (Malus $\times$ domestica Borkh.). Scientia Horticulturae, 231, 73-81. https://doi.org/10.1016/j.scienta.2017.12.006

[29] Bai, T., Li, C., Li, C., Ma, F. and Shu, H. (2013) Contrasting Hypoxia Tolerance and Adaptation in Malus Species Linked to Differences in the Stomatal Behavior and Photosynthesis. Physiologia Plantarum, 147, 514-523. https://doi.org/10.1111/j.1399-3054.2012.01683.x

[30] Ventre-Lespiaucq, A., Flanagan, N.S., Ospina-Calderón, N.H., Delgado, J.A. and Escudero, A. (2018) Midday Depression vs. Midday Peak in Diurnal Light Interception: Contrasting Patterns at Crown and Leaf Scales in a Tropical Evergreen Tree. Frontiers in Plant Science, 9, 727. https://doi.org/10.3389/fpls.2018.00727

[31] Guha, A., Chhajed, S.S., Choudhary, S., Sunny, R., Jansend, S. and Baruab, D. (2018) Hydraulic Anatomy Affects Genotypic Variation in Plant Water Use and Shows Differential Organ Specific Plasticity to Drought in Sorghum bicolor. Environmental and Experimental Botany, 156, 25-37. https://doi.org/10.1016/j.envexpbot.2018.08.025

[32] Biswal, A.K., Pattanayak, G.K., Pandey, S.S., Leelavathi, S., Reddy, V.S. and Tripathy, B.C. (2012) Light Intensity-Dependent Modulation of Chlorophyll b Biosynthesis and Photosynthesis by Overexpression of Chlorophyllide a Oxygenase in Tobacco. Plant Physiology, 159, 433-449. https://doi.org/10.1104/pp.112.195859

[33] Ashraf, M. and Harris, P.J.C. (2013) Photosynthesis under Stressful Environments: An Overview. Photosynthetica, 51, 163-190. https://doi.org/10.1007/s11099-013-0021-6

[34] Falqueto, A.R., Cassol, D., Magalhăes Júnior, A.M., Oliveira, A.C. and Bacarin, M.A. (2009) Growth and Assimilates Partitioning in Rice Cultivars Differing in Grain Yield Potencial. Bragantia, 68, 563-571. https://doi.org/10.1590/S0006-87052009000300002

[35] Houimlisi, D.M. and Mouhandes, B.D. (2010) Effects of 24-Epibrassinolide on Growth, Chlorophyll, Electrolyte Leakage and Proline by Pepper Plants under $\mathrm{NaCl}$-Stress. EurAsian Journal of BioSciences, 4, 96-104.

https://doi.org/10.5053/ejobios.2010.4.0.12 